http://www.jfas.info

\title{
ANALYZING THE PSYCHOMETRIC PROPERTIES OF THE CLASSROOM PERCEPTION SCALE
}

\author{
A. Eskandari ${ }^{1}$ and M. Mohammadipour ${ }^{2, *}$ \\ ${ }^{1}$ Department of Counseling, Quchan Branch, Islamic Azad University, Quchan, Iran \\ ${ }^{2}$ Department of Psychology, Quchan Branch, Islamic Azad University, Quchan, Iran
}

Published online: 15 June 2016

\begin{abstract}
Introduction: The purpose of study was to evaluate the psychometric characteristics of perceived scale of the class in Iranian society.

Method: The study is correlation type (factor analysis). The study used exploratory and confirmatory factor analysis which is a technique to study the structure of a set of data that has several pre-conception about the discovery of a questionnaire items. The study sample was 300 male and female students of high school in the city of Mashhad in 2015 that were randomly stratified and completed the perceived scale of the class.

Data were analyzed by using exploratory and confirmatory factor analysis.

Findings: The results of the factor analysis method tend to have Direct Oblimin rotation showed four factors of perceived the class and were fitted by confirmatory factor analysis. Internal consistency reliability coefficients like Alpha Cronbach for 31 items and four factors including interest, challenge, selecting and enjoying, respectively has the amount of $0.77,0.66$, $0.80,0.91$ and total scale of the perception of class was 0.90 which is satisfactory.
\end{abstract}

Author Correspondence, e-mail: mmohamadipoor@yahoo.com doi: http://dx.doi.org/10.4314/jfas.v8i2s.165 
Discussion: The results of the factor analysis are consistent with previous research and considering the validity and reliability of the perception of the gentry' class therefore this questionnaire can be a useful tool for evaluating the perception of students from the classroom.

Keywords: Perception of class; factorial validity; reliability; psychometric.

\section{INTRODUCTION}

Human organize his perception of the environment due to various features. A person in different situations has different behavior that is due to the specific characteristics of each location environment. School as a social institution is part of a special community that has unique atmosphere and specific characteristics.

A classroom as a main part of the school has different aspects which generally makes the class environment. Each student that enters school has specific characteristics, personality, cultural background, social and familial differences and different talents. Each one of the teachers is different from one another and each class has its own physical properties. A combination of all of these features and the interaction between them make up the class psychology environment. Meanwhile school curriculum, teaching methods of teacher, educational goals at the macro level, the expectations of parents and the school community is effective on class environment (Bridge, 1391).

The classroom environment or situation is a place that learners and teachers interact with each otherand it is using a variety of tools and information resources to pursue benefit of learning activities. These interactions at multiple levels are including the interaction between teachers students, student - teacher, student - student as well as the general mood in class (Gazelle, 2006).

The study of perception of the class is based on the assumption that student perception of the environment is related to personal and underlying characteristics. And this will have effect on the way he thinks about his social world and his attitude toward the environment. Accordingly, the perception of students from learning environment also has effect on participating in classroom activities and their relationships with peers (Patrick et al, 2007). 
Researches that were conducted over the last 30 years have shown that the perception of the classroom is a significant determinant of students learning (Fraser, 1998). When students have a positive perception of their own class environment, they have better performance and more positive attitudes towards their own learning (Dorman, 2005). The students' perception of teacher behavior acts as an important mediator between teacher behavior and student learning performance (Dan break, 2001). In addition, students act according to their teacher's behavior. Students' perception of school and class will have effect on academic and social motivation, beliefs about themselves, learning strategies, participating in learning activities, help-seeking behavior, academic achievement and emotional functioning (Turner et al, 2002).

From another perspective, Ames (1992) in a comprehensive review of the literature on the role of classroom structures in goals and motivation of students used class structures instead of classroom perceptions. He believed that classroom structures are affecting different motivation variables. This structure is including - but not limited to - design assignments and learning activities, evaluation experiences, and application of rewards and the role of power and responsibility. According to Ryan and Grolnick (1986), no matter what the teacher is more involved in decision-making, they will develop a more adaptive pattern of positive motivation. Perceived control is significant and important factors that have effect student engagement in learning and effective learning quality (Nolen and Haladyna, 1990).

According to current views, class structure based on the teacher's goals and values are formed, but its effects on motivation and performance, students will depend on how their perception of classroom. Blackburn (1992) offers three types of perception classes that include:

1- Motivational tasks significantly, relevant and engaging for learners specifies the class assignments.

2- Mastery evaluation, the evaluation of how pervasive and good cognitive performance in class and learning shows social comparison and competition that is emphasized.

3- Autonomy support, specifies the amount of support that teacher thinks that students with the opportunity to choose and encouraged to take responsibility for their own learning puts self-regulation (Karsheki, 2010).

Perceptions of school activities or classes, a wide range of processes, beliefs and perceptions 
of control, autonomy, and choice of support and pleasure (Gentry, Gable, Rizza, 2002). Perceptions of school activity are influenced by several factors and consequences and are certain to follow. In examining the perceptions of class, they found basic and gender differences for high school students (compared to elementary students) class educational activities are less enjoyable and appealing and they have fewer choices. Girls knew their classes more enjoyable and attractive than boys (Gentry et al, 2002).

Andermen and Midgley (1997) stated that classroom environment and school, school administration and training method of teachers have undeniable effects on school functions and cognitive processes. One of the important outcomes school environments is students' perceptions which play an important role in motivation, recognition and performance of students. Eccles and Wigfield (2002) found that high school students who perceived that their teachers were more controlling and teachers gave them fewer decision-making opportunities, had low levels of self-efficacy and motivation (Kadivar, 2010).

Therefore, perceptions of classroom environment are considered relevant critical variable in education and other areas.In order to strengthen and improve their learning and factors that influence this perception, it is crucial for teachers and education researchers. Introduction an appropriate tools to assess these variables and demonstrate its necessity in different fields of study, is worth noting. Accordingly, the present survey questionnaire was introduced perception of class Gentry and Owen, together with a report on the results and the validity and reliability will be among the students of Mashhad. The purpose of this study was to analyze psychometric characteristics questionnaire of class perception. Method: The study is correlation type (factor analysis). In this study, exploratory and confirmation factor analysis were used that is a techniques to study the structure of the data set, which has several pre-conception about the discovery of a questionnaire. The statistic population of study included 300 students (150 boys and 150 girls). Random sampling was used to select schools from district 1 of Mashhad. Data tools included Perception questionnaire of Gentry Class (2002) is, Perception questionnaire of classroom consists of 31 questions. Items that are used in this questionnaire reflect the individual impression of class and class activities. Scoring the questionnaire is based on 5-point Likert scale and is from always to never. A minimum score 
is 31 and a maximum is 155 . A score between 31 and 62 score is perceptions of environment unfavorable classroom, and the score between 62 and 93: is the perception of environment of normal classroom.

The score higher than 93: is a perception of environment from desirable classroom. To confirm the validity and reliability, indices of confirmatory factor analysis reported in the original source $($ RSMEA $=0.044$ and GFI $=0.95)$, are indicating the reliability of the questionnaire (Gentry, Gable, Risa, 2002). Overall validity that is obtained by Cronbach's final performance is $(0.93)$. The validity of subscales the questionnaire, respectively are $(0.82)$, (0.66), (0.76) and (0.87) (Salehi and Karsheki, 2014). Factor analysis was used to analyze the data.

\section{FINDINGS}

Table 1. Descriptive indicators of classroom perception questionnaire and sub-test (interest, challenge, choice and fun)

\begin{tabular}{ccccc}
\hline Indicators & Interest & Challenge & Choice & Enjoyment \\
\hline Numbers & 300 & 299 & 301 & 301 \\
\hline Mean & 2.79 & 3.13 & 3.35 & 3.10 \\
\hline Standard error & 0.04 & 0.05 & 0.08 & 0.09 \\
\hline Standard deviation & 0.76 & 0.8 & 1.32 & 1.71 \\
\hline Variance & 0.59 & 0.64 & 1.74 & 2.94 \\
\hline Skewness & 4 & -0.410 & -0.092 & -0.576 \\
\hline Kurtosis & 1.22 & -0.183 & 0.221 & 0.402 \\
\hline Minimum & 1 & 1 & 1 & 1 \\
\hline Maximum & 5 & 5 & 5 & 5 \\
\hline
\end{tabular}

According to cognitive subscale scores of the class, students' tendency to all four variables is relatively at the same level. Although the average scores of choice variables is more than other variables and average scores of interest variable is lower than other variables. Based on the above data, it can be said that the students make their choice of discussion they would 
have liked more and pay less attention to things that are not interested in them. Also according to the amount of skewed and stretch between -2 to +2 therefore the distribution of scores on these variables are normal.

In order to evaluate the adequacy of sampling and hypothesis of no enough correlation between the variables from sufficient criterion of Kaiser-Meyer-Elkin (KMO) sampling adequacy and Bartlett's test of globosity was used. The results are presented in table (2-4):

Table 2. The size of KMO and Bartlett's test of globosity

\begin{tabular}{ccc}
\hline KMO & Bartlett's test & Significant Level \\
\hline 0.948 & 6491.25 & 0.000 \\
\hline
\end{tabular}

According to the table above, sufficient sampling was 0.948 that show the data are suitable for principal components analysis. Similarly, Bartlett's test of globosity was achieved 6491.25 that are significant at 0.000 level. And shows there is enough correlation for conducting between variables, and the null hypothesis of not having enough correlation between the variables was rejected.

Table 3. Perception of statistical indicators of class 4 after Varimax rotation in component method

\begin{tabular}{cccc}
\hline Factors & eigenvalue & \% of variance & \% Cumulative \\
\hline 1 & 8.042 & 25.943 & 25.943 \\
\hline 2 & 3.142 & 10.135 & 36.78 \\
\hline 3 & 3.017 & 9.731 & 45.809 \\
\hline 4 & 2.775 & 8.953 & 54.762 \\
\hline
\end{tabular}

The results of exploratory factor analysis with oblique rotation show 4 items that are of the 8 items of interest, challenge 9 items, choice 7 items and enjoy 7 items, has identified. The first 4 items of questionnaire explain about 54.76 percent of the variance in perceptions of class. The special value for important and significant factors from the first to fourth are respectively; $8.04,3.14,3.017$ and 2.77 and totally are 16.96 . The amount of explained variance for first to 
fourth factors respectively are; 25.94, 10.35, 9.73, 8.95 and totally are 54.76. The result implies the saturation of the questionnaire from 4 factors that has a larger share of the total variance and three more detailed questionnaires.

Fitting Model parameters are provided below to check the suitability of confirmatory factor analysis model in the table (4-6):

Table 4. Summary of four-factor Indicators of class perception questionnaire model

\begin{tabular}{lccccccc}
\hline Model & $x^{2}$ & df & RMSEA & RMR & GFI & AGFI & CFI \\
\hline $\begin{array}{l}\text { Measured } \\
\text { model }\end{array}$ & $1522 / 079$ & 521 & $0 / 08$ & $0 / 07$ & $0 / 93$ & $0 / 85$ & $0 / 91$ \\
\hline
\end{tabular}

Confirmatory factor analysis was conducted by AMOS-21 has shown that the model is supposed to be fitted enjoyable. Because the $x^{2}$ amount at 000 level $0<\mathrm{P}$ was not significant. K2 Index of degrees of freedom is smaller than 3. This means that there is compliance and fitting between hypothesized model and measurement model (The $x^{2}$ amount should not be meaningful). Also, according Tabaknick (2007) the root mean square error of approximation (RMSEA) should be less than 0.1 (smaller than 0.05 is good and 0.08 is appropriate). Because the value of RMSEA is equal to 0.08, it reflects the model is fitted. Also fit index (GFI) and comparative fit index (CFI) should be bigger than 0.9 which is happened. In sum, we conclude that the supposed model is fitted enjoyably. This means that the underlying structure using class perceptions is confirmed. Cronbach's alpha was used to estimate the reliability of the results is shown in Table 4-7:

Table 5. The reliability of classroom Perception and sub-tests with Cronbach's alpha

\begin{tabular}{lccccc}
\hline $\begin{array}{l}\text { Indexes } \\
\text { scales }\end{array}$ & total & Interest & challenge & Choice & Enjoyment \\
\hline $\begin{array}{l}\text { Cronbach's } \\
\text { alpha }\end{array}$ & $0 / 901$ & $0 / 776$ & $0 / 662$ & $0 / 801$ & $0 / 91$ \\
\hline $\begin{array}{l}\text { Question } \\
\text { numbers }\end{array}$ & 31 & 8 & 9 & 7 & 7 \\
\hline
\end{tabular}


As in the table above, the reliability of classroom Perception and sub-tests with Cronbach's alpha were calculated and the sub-scales of enjoyment had the highest reliability and challenge had the lowest reliability. However, the entire class perception questionnaire and its subscales have high reliability.

\section{DISCUSSION AND CONCLUSION}

Given the importance of this study on perception of class, some psychometric properties of the questionnaire perception of class, that Gentry (2002) is designed and built in Iranian students have explored. Dorman (2009), has reported the validity of some psychometric properties of this tool. In various studies, such as research Okun (2008) and Allen and Fraser (2007) had reported that exploratory factor analysis and confirmatory factor analysis and other relevant parameters are also provided, that implies the tools were favorable.

Based on the results, all the questions of the scales of interest, challenge, choice and fun were loaded in their aspects. Kumeri and Li described coefficients of 0.70 excellent, 0.63 very good, 0.55 good and 0.32 are trivial. According to this criterion most of the coefficients are located in the good to excellent category $(0.395$ to 0.788$)$. As a result, a four-factor structure was obtained for this area (with the defined variables in the table above for each factor) that confirmed the structure of this questionnaire and approved the above analyzes, and the validity of the questionnaire. Therefore the hypothesis is confirmed by 99 percent of selection. In this study, consistent with numerous studies to confirm factor analysis of this scale has been conducted in other countries, confirmatory factor analysis method was used to assess the validity of various subscales of class perception of Iranian student sample. The results confirm that the data is consistent with the factor structure and provide desirable and reliable construct validity. And therefore the fitness of model that was reported by Fraser, Fisher, and Mr Rubin (1996) and Dorman (2009) was confirmed.

In other words we can say that the data of this study is consistent with the model and the estimated parameters showed a good fit to the data model. The findings of this are consistent with related research results, therefore it can be concluded that the scientific studies and efforts of Gentry and cooperation in the preparation of the questionnaire perceptions of 
classroom environment, has been effective. And this questionnaire is valid and useful tool that can help students' perceptions of class in different fields of study and assess the various cultures and societies; based on this research, studying the theoretical principles and their application in question and preliminary studies and finally the final questionnaire was conducted with scientific precision and psychometric properties calculated in this study and other studies, confirms this claim.

In this study, Cronbach's alpha coefficients were calculated to estimate the reliability perceptions of class. Cronbach's alpha coefficients for factors results indicate that the tool also has an acceptable internal consistency and reliability (Cronbach's alpha) of all those subscalesis also acceptable (interest: 0.77, Challenge: 0.66, choose: 0.80, fun: 0.91). According to these findings, it was concluded class perception of the gentry in the Iranian sample, had high reliability and internal consistency and it is acceptable.

Several studies also illustrated its relationship with academic and social motivation, beliefs about themselves, learning strategies, participating in learning activities, help-seeking behavior, academic achievement, and emotional functions (Anaxcels et al, 1993; Coperminc et al, 1997, Roser et al, 1998; Ryan et al, 1998). Thus, the questionnaires conducted various researches to improve the quality of education and create a pleasant and attractive learning environment for students.

Thereforeit can be stated that class perception questionnaire has satisfactory reliability and validity for using in an Iranian sample and it can be used as a tool to assess classroom perceptions of students of the environment.

\section{REFERENCES}

[1]Habibi Kalibar, R; Abdollah Vand, K (2014) Examine the relationship between perceived classroom environment with high school students' motivational mentioned, the first National Conference on Sustainable Development in Psychology, Social and Cultural Studies, Tehran, October Arvand institutions of higher learning. 
[2]Salehi, M; Karsheki; H (2014) Evaluation of the role of perception components class quality components incompatibility high school female students in Mashhad. . School psychologists, No. 4, pp. 93 and 110.

[3]Karsheki; H, Khatazi, A, Ghazi Tababyi, M (2008) To investigate the relationship between perceived school environment and development objectives; Ferdowsi University of Psychology and Education Studies, Volume 9, 79-93.

[4]Nikdel, F; Kadivar, Parvin; F, V; Karimi. Y (2010) Psychometric Evaluation of class Perception Survey quarterly to measure educational scientific research; the first year, S.31-53

[5]Rafei. A (2011). The relationship between perceptions of classroom environment with social adjustment and academic performance in third grade female students' Aran and Bidgol. Allameh Tabatabai University - Faculty of Psychology and Educational Sciences. Masters.

[6]Den Brok, P., Fisher, D. L., Rickards, T., \& Bull, E. (2006). Californian sciencestudents' perceptions of their classroom learning environments. EducationalResearch and Evaluation, 12, 3-25.

[7]Dorman, Jeffrey P.(2009). Partitioning the variance in scores on classroomenvironment instruments. Australian Journal of Educational \& DevelopmentalPsychology. Vol 9, 2009, pp 18-31.

[8]Fraser, B. J., \& Aldridge, J. L. (2001). Junior secondary mathematics student'slearning environment and satisfaction in Brunei Darussalam. Paper presented atthe Annual Conference of the Australian Association for Research in Education,Western Australia.

[9]Fraser, B. J., \& Chionh, Y. H. (2000). Classroom environment, self-esteem,achievement, and attitudes in geography and mathematics in Singapore. Paperpresented at the annual meeting of the American Educational ResearchAssociation, New Orleans, LA.

[10]Fraser, B.J. (1998). Classroom learning environments: Development, validity, andapplications. Learning Environments Research, 1, 7-33. 
[11]Fraser, B.J.; Fisher, D.L.; McRobbies, C.J. (1996) Development, validation and useof personal and class forms of a new classroom environment instrument. Paperpresented at the Annual of the American Educational Research Association, NewYork, USA.

[12]Gazelle, H. (2006). Class climate moderates peer relations and emotionaladjustment in children with an early history of anxious solitude: A Child xEnvironment Model. Developmental Psychology, 42, 1179-1192.

[13]Gentry, M. Gable, R. K. \& Rizza, M. G. (2002). Students' perceptions of classroom activities. Are there grade-level and gender differences. Journal of Educational Psychology, 94, 539-544.

[14]Patrick, H., Ryan, A., \& Kaplan, A. (2007). Early adolescents' perceptions ofclassroom environment, motivation, and beliefs. Journal of EducationalPsychology, 99, 83-98.

[15]Turner, J. E., Husman, J., \& Schallert, D. L. (2002). The importance of students'goals in their emotional experience of academic failure: Investigating theprecursors and consequences of shame. Educational Psychologists, 37(2), 79-89.

[16]Sungur, S. (2009). The Role of Classroom Environment Perceptions inSelf-Regulated Learning and Science Achievement. Elementary Education Online, 8(3), 883-900.

\section{How to cite this article:}

Eskandari A and Mohammadipour M. Analyzing the psychometric properties of the classroom perception scale. J. Fundam. Appl. Sci., 2016, 8(4S), 2048-2058. 